\title{
Choline deficiency induces apoptosis in primary cultures of fetal neurons
}

\author{
CHI-LIANG E. YEN, MEI-HENG MAR, RICK B. MEEKER,* \\ ALDA FERNANDES,* AND STEVEN H. ZEISEL ${ }^{1}$ \\ Department of Nutrition, School of Public Health and School of Medicine, \\ *Department of Neurology, School of Medicine, University of North Carolina, \\ Chapel Hill, North Carolina 27599-7400, USA
}

\begin{abstract}
Treatment of rats with choline during brain development results in long-lasting enhancement of spatial memory whereas choline deficiency has the opposite effect. Changes in rates of apoptosis may be responsible. We previously demonstrated that choline deficiency induced apoptosis in PG12 cells and suggested that interruption of cell cycling due to a decrease in membrane phosphatidylcholine concentration was the critical mechanism. We now examine whether choline deprivation induces apoptosis in nondividing primary neuronal cultures of fetal rat cortex and hippocampus. Choline deficiency induced widespread apoptosis in primary neuronal cells, indicating that cells do not have to be dividing to be sensitive to choline deficiency. When switched to a choline-deficient medium, both types of cells became depleted of choline, phosphocholine and phosphatidylcholine, and in primary neurons neurite outgrowth was dramatically attenuated. Primary cells could be rescued from apoptosis by treatment with phosphocholine or lysophosphatidylcholine. As described previously for PC12 cells, an increase in ceramide (Cer) was associated with choline deficiency-induced apoptosis in primary neurons. The primary neuronal culture appears to be an excellent model to explore the mechanism whereby maternal dietary choline intake modulates apoptosis in the fetal brain.-Yen, C.-L. E., Mar, M.-H., Meeker, R. B., Fernandes, A., Zeisel, S. H. Choline deficiency induces apoptosis in primary cultures of fetal neurons. FASEB J. $15,1704-1710(2001)$
\end{abstract}

Key Words: · primary neurons • hippocampus • PC12 cells

Choline is a nutrient essential for normal function of all cells (1). In addition to being the precursor for acetylcholine synthesis, it is a major methyl group donor $(1,2)$. Phospholipids containing choline, such as phosphatidylcholine (PtdCho) and sphingomyelin, are not only major structural components of cell membranes (3), but also reservoirs for lipid second messengers (diacylglycerol and ceramide, or Cer) that modulate cell growth and apoptosis $(4,5)$.

Studies in rodents suggest that dietary intake of choline early in life can diminish the severity of memory deficits in aged animals. Memory function of adult rats can be permanently altered by choline supplementation in utero, even though there is no supplementation throughout the rest of their lives (6-9). The choline-related memory changes are correlated with altered distribution and morphology of septal neurons in the adult animals (10) and with changes in the electrophysiological properties of the hippocampi in supplemented animals $(11,12)$. The memory changes observed in choline-supplemented rats are also correlated with changes in the neurotransmitter-related enzymes present in the adult brains $(13,14)$. The likely mechanism explaining these differences in memory involves choline-mediated alterations in the birth, migration, and death of cells in the memory centers of brain during critical periods in their development (15, 16).

We previously reported that choline deficiency induced apoptosis in fetal rat hippocampus (day 18 gestation) $(15,17)$ and in a variety of cell types in culture $(18,19)$. We proposed that induction of apoptosis was caused by a decrease in membrane PtdCho concentration $(19,20)$ because this choline ester is needed for normal progression through the cell cycle (21). To test this hypothesis we wanted to study the effects of choline deficiency in cells that were not dividing. For this reason, and because we seek a model system that more closely describes events that might occur in fetal brain, we now characterize the effects of choline deficiency in primary culture of postmitotic fetal rat brain neurons derived from hippocampus and cortex.

\section{MATERIALS AND METHODS}

Cell culture

PC12 cells

PC12 cells were a kind gift from Dr. J. P. O'Bryan at the University of North Carolina at Chapel Hill. Cells were maintained in DMEM/F12 medium (Atlanta Biologicals,

\footnotetext{
${ }^{1}$ Correspondence: University of North Carolina at Chapel Hill, CB\#7400, Room 2213, McGavran Greenberg Hall, Chapel Hill, NC 27599-7400, USA. E-mail: steven_zeisel@unc.edu
} 
Norcross, GA) containing $10 \%$ fetal bovine serum (Life Technologies, Grand Island, NY). Because choline and PtdCho are present in sera, a chemically defined medium (DMEM/F12 with modified N2 supplement) was used for both experimental and control groups of cells. The components of the defined medium and the experimental procedure have been reported previously (19).

\section{Primary neuronal culture}

Fetal brains were obtained from timed pregnant SpragueDawley rats (Charles River, Raleigh, NC) at embryonic day 18. Both sexes of fetuses were used. After removing dura-arachnoid membranes, the cortexes and hippocampi were isolated and incubated in $5 \mathrm{ml}$ calcium, magnesium-free Hank's balanced salt solution containing $2.5 \mathrm{U} / \mathrm{ml}$ dispase and 2 $\mathrm{U} / \mathrm{ml}$ DNase. Dissociated cells were counted and seeded on poly-D-lysine-coated coverslips at a density of $\sim 150,000$ cells/ $\mathrm{cm}^{2}$ in minimal essential medium containing $10 \%$ fetal bovine serum and $20 \mu \mathrm{g} / \mathrm{ml}$ gentamicin (Sigma, St. Louis, MO). Cells were then shifted into the experimental media (same as those used for PC12 cells except for the addition of B-27 supplement; Life Technologies) $3 \mathrm{~h}$ after seeding.

\section{Immunohistochemistry}

\section{Neurofilament}

Primary cells in culture for 4 days were prepared for immunocytochemical staining of neurofilaments. Cells were fixed in ice-cold methanol:acetone (1:1) and washed with phosphate-buffered saline (PBS) before incubating in $0.6 \% \mathrm{H}_{2} \mathrm{O}_{2}$ for $20 \mathrm{~min}$. After blocking with $3 \%$ normal goat serum prepared in PBS for $1 \mathrm{~h}$, cells were incubated overnight at $4^{\circ} \mathrm{C}$ with a mouse monoclonal anti-neurofilament antibody (68 $\mathrm{kDa}, 1: 5000$; Boehringer Mannheim, Indianapolis, IN). The antibody was washed away the following day with PBS and the cells were incubated in biotinylated goat anti-mouse IgG (1:200) at room temperature for $1 \mathrm{~h}$. After washing with PBS, the cells were reacted with $\mathrm{ABC}$ reagent (Vector Labs, Burlingame, CA) and the antibody was visualized with diaminobenzidine (DAB, $0.5 \mathrm{mg} / \mathrm{ml}$ ) in the presence of $0.01 \% \mathrm{H}_{2} \mathrm{O}_{2}$. The cells were then counterstained with methyl green.

\section{MAP-2}

Cells fixed in $4 \%$ paraformaldehyde for $15 \mathrm{~min}$ at room temperature were stained as described for neurofilament staining except that cells were incubated with a 1:5000 dilution of mouse monoclonal anti-MAP-2 antibody (Boehringer Mannheim). DAB was used as a chromogen as described above.

\section{Flow cytometry for cell cycle analysis}

Cells were trypsinized, dislodged, and washed with PBS twice. Cell numbers were determined and $2 \times 10^{6}$ cells were fixed by slowly adding them to ethanol (final concentration $70 \%$ ) for at least $18 \mathrm{~h} ; 30 \mathrm{~min}$ before analysis, cells were stained with propidium iodide $(50 \mu \mathrm{g} / \mathrm{ml})$ in PBS containing $100 \mathrm{U} / \mathrm{ml}$ RNase A. The flow cytometer FACscan (Becton-Dickinson, San Jose, CA) and the software Mofit (Verity Software House, Topsham, ME) were used to analyze the percentage of cells in each phase of the cell cycle.

\section{Determination of apoptosis}

Morphological analysis

Apoptosis was assessed in both attached and detached PC12 cells, which were collected and deposited onto glass slides using a cytocentrifuge. Cells were then fixed with methanol, stained with hematoxylin (Fisher, Fair Lawn, NJ), and mounted with Permount (Fisher). Slides were examined under a light microscope and the percentage of apoptotic cells was determined by counting at least 200 cells in four replicate cultures per treatment. Cells with fragmented nuclei (multiple, small hematoxylinophilic bodies) were defined as apoptotic. Primary cells grown on poly-D-lysine-coated glass chamber slides were fixed in $4 \%$ paraformaldehyde and then incubated with the nuclear stain 4,6-diamidino-2-phenylindole $(1 \mu \mathrm{g} / \mathrm{ml}$ DAPI, Sigma). The percentages of apoptotic cells were determined under fluorescent microscope. Detached cells could be lost during the staining process. We found that the majority of primary cells remained attached after $48 \mathrm{~h}$ of nutrient deprivation and that the majority of detached cells were apoptotic. Therefore, the observed differences between control and choline-deficient cells could have been underestimated. Alternatively, we identified apoptotic cells using TUNEL staining, in which DNA fragments in the nuclei were labeled with FITC-coupled nucleotides and normal nuclei were counterstained with ethidium homodimer. Fluorescein-FragEL ${ }^{\mathrm{TM}}$ DNA fragmentation detection kit (Oncogene Research Products, Cambridge, MA) was used and the manufacturer's protocol was followed, with the addition of ethidium homodimer as counterstaining.

\section{DNA fragmentation (DNA ladders)}

Samples $\left(2 \times 10^{6}\right.$ cells $)$ were lysed in $200 \mu$ lysis buffer containing $50 \mathrm{mM}$ Tris ( $\mathrm{pH} 7.4), 10 \mathrm{mM}$ EDTA, $0.5 \%$ $\mathrm{N}$-laurosarcosine (Sigma) and incubated for $3 \mathrm{~h}$ with 0.5 $\mathrm{mg} / \mathrm{ml}$ protease $\mathrm{K}$ (Boehringer Mannheim) at $65^{\circ} \mathrm{C}$. Cells were then incubated for $1 \mathrm{~h}$ with $24 \mathrm{U} / \mathrm{ml}$ DNase-free RNase (Boehringer Mannheim) at $50^{\circ} \mathrm{C}$. After extraction with an equal volume of phenol/chloroform/isoamyl alcohol (25: $24: 1, \mathrm{v} / \mathrm{v}$ ) and precipitation with 2 volumes of absolute ethanol, the DNA was resuspended in $100 \mu \mathrm{l} 10 \mathrm{mM}$ Tris buffer ( $\mathrm{pH}$ 7.4) containing 1 mM EDTA. The DNA concentration was determined by measurement of optical density at $260 \mathrm{~nm}$. Ten micrograms of DNA were subjected to electrophoresis on a $1.2 \%$ agarose gel at $100 \mathrm{~V}$ for $2 \mathrm{~h}$. DNA was visualized and photographed under UV light after ethidium bromide staining.

\section{Biochemical determinations}

Samples were collected at various time intervals after cells had been treated with experimental media. To ensure an equal number of cells in both the experimental and control groups, DNA was measured as a basis for normalization using a fluorometric method (22). After addition of ${ }^{14}$ C-labeled internal standards, choline, phosphocholine, and glycerophosphocholine in the aqueous phase of cell extracts (23) were separated using high-performance liquid chromatography (HPLC) (24); phosphatidylcholine in the organic phase was separated using thin-layer chromatography (24). A $\left[{ }^{2} \mathrm{H}-\right.$ methyl]-labeled internal standard for each metabolite was added to permit correction for recovery during analysis of choline moiety by a gas chromatography/mass spectrometry assay (24).

To determine the effect of choline deprivation on intracellular levels of Cer, lipid was extracted and assayed using the 

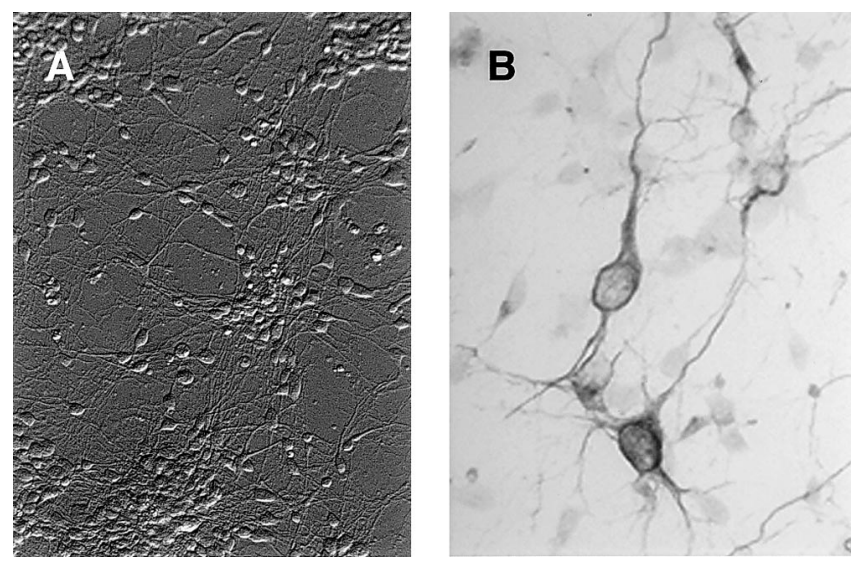

Figure 1. Primary neurons cultured in a chemically defined medium with added choline for 4 days after being isolated from E-18 rat fetal brains. Brain cells were isolated and primary neuronal cultures were established as described in Materials and Methods. A) Hoffmann modulation contrast image showing neurons with healthy cell bodies and processes $(200 \times)$. B) Neurons stained with a neurofilament antibody $(400 \times)$.

HPLC method described by Previati et al. (25). Cells were first fixed on the culture dish with $1.5 \mathrm{ml}$ methanol, scraped off the plate, and transferred into a $15 \mathrm{ml}$ centrifuge tube (Falcon). After adding $3 \mathrm{ml}$ chloroform, the samples were mixed and incubated overnight at $-20^{\circ} \mathrm{C}$. Cell debris was pelleted by centrifugation, further extracted twice with $1 \mathrm{ml}$ chloroform/methanol (1:1 and 1:2 sequentially), and extracts were combined. The organic phases were separated after adding $1 \mathrm{ml}$ water and the aqueous phases were reextracted with $2 \mathrm{ml}$ chloroform. The organic phases were then combined and dried in a concentrator (Savant). The residues were dissolved in $100 \mu \mathrm{l}$ anhydrous chloroform and derivatized with $10 \mu \mathrm{l}$ of $100 \mathrm{mM}(\mathrm{S})-6$ methoxy- $\alpha$-methyl-2naphthaleneacetic acid (Sigma), $10 \mu \mathrm{l}$ of $100 \mathrm{mM} \mathrm{N}, \mathrm{N}^{\prime}$ dicyclohexylcarbodiimide (Sigma), and $10 \mu \mathrm{l}$ of $100 \mathrm{mM}$ 4-dimethylaminopyridine at $-20^{\circ} \mathrm{C}$ for at least $3 \mathrm{~h}$. After incubation, the samples were dried to stop the reaction. The samples were resuspended in $15 \mu \mathrm{l}$ chloroform and extracted with $2 \mathrm{ml}$ hexane. The supernatants were transferred to new screw-capped tubes containing $5 \mathrm{ml} \mathrm{MeOH} /$ water (4:1) and mixed vigorously. After centrifugation, the upper phase was collected and the extraction procedure was repeated. The upper phases were combined and dried. The dried samples were dissolved in $1 \mathrm{ml}$ of hexane and $50 \mu \mathrm{l}$ of the samples was injected onto HPLC. Derivatized ceramides were resolved on an Econosphere CN, $250 \times 4.6 \mathrm{~mm}$ column (Alltech, Deerfield, IL) equipped with a guard column with Discovery Cyano cartridge (Supelco, Bellefonte, PA). The mobile phase was delivered at the flow rate of $2 \mathrm{ml} / \mathrm{min}$. The column was initially equilibrated in $97 \%$ mobile phase A (hexane) and $3 \%$ mobile phase B (3\% isopropanol in hexane). It was first run with a linear gradient to $10 \% \mathrm{~B}$ from 0 to $4 \mathrm{~min}$ after injection and then an isocratic run at $10 \%$ B for $5 \mathrm{~min}$, followed by a linear gradient to $100 \%$ B from 9 to $18 \mathrm{~min}$. Cer concentration was quantified using a standard curve of known amounts of Cer.

To determine whether cells could be rescued from choline deficiency-induced apoptosis, they were cultured as described previously in choline-free medium for $36 \mathrm{~h}$. At this time cells were either left in choline-free medium (deficient) or switched to medium containing either $50 \mu \mathrm{M}$ lysophosphatidylcholine (palmitoyl; Sigma) in $1 \mathrm{mM}$ BSA, $100 \mu \mathrm{M}$ phosphocholine (Sigma) in basal medium, or $100 \mu \mathrm{M}$ phosphati- dylcholine (dipalmitoyl; Sigma) prepared by sonicating in basal medium. At 72 h, viable cell numbers were determined by trypan blue exclusion and apoptosis was determined by TUNEL assay.

\section{Statistics}

We used one-way analysis of variance, followed by the Dunnett's critical difference test to determine statistical significance between the treatment groups and control at time 0 . Comparisons for each pair were determined with Student's $t$ test (JMP Version 2, SAS, 1989).

\section{RESULTS}

\section{Primary neuronal culture}

The majority of the cells isolated from the E18 cortex and hippocampus attached onto poly-D-lysine-coated matrix within an hour. When cultured in the chemically defined medium containing choline, most of the cells exhibited the morphology of healthy neurons (Fig. 1A). Immunocytochemical staining of the neuronspecific marker neurofilament (Fig. $1 B$ ) or MAP-2 (data not shown) identified most cultured cells as neurons. When assessed by flow cytometry, more than $92 \%$ of primary cells were in G0/G1 phases of the cell cycle compared with less than $70 \%$ PC12 cells in these phases (Fig. 2). Accordingly, only $2 \%$ of primary cells were in G2/M phases after $24 \mathrm{~h}$ in culture, whereas $8 \%$ of PC12 cells were in these phases of the cell cycle at the same time point. Tritiated thymidine incorporation into DNA was assessed. Negligible amounts of label were incorporated into DNA of primary cells in culture ( $0.02 \%$ of added label was incorporated) over a period of 24 h. In contrast, dividing PC12 cells incorporated most of the label. Finally, we measured DNA concentration/plate in our primary cell cultures and found no accumulation of DNA ( $24 \mathrm{~h}=37.2 \mu \mathrm{g} ; 48 \mathrm{~h}=39.9 \mu \mathrm{g} ; 72$ $\mathrm{h}=36.1 \mu \mathrm{g})$. These data support our suggestion that these primary cells are not dividing in culture.

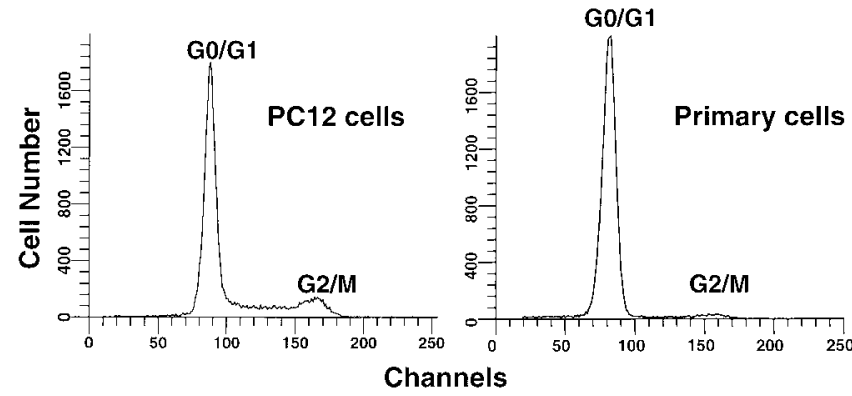

Figure 2. Most primary cells are at the $G 0 / G_{1}$ phase of cell cycle while PC12 cells progress through the cell cycle. Cell cycle status of PC12 cells and primary cells in culture was determined by flow cytometry as described in Materials and Methods. $24 \mathrm{~h}$ after cells were placed in culture, cells were detached and fixed in $70 \%$ ethanol overnight before being stained with propidium iodide. 
Apoptosis

When choline was not included in the chemically defined medium, apoptosis was induced. Compared with cells grown in the complete medium (Fig. 3A), more primary neurons exhibited apoptotic morphology (condensed chromatin and fragmented nuclei) when grown in the same medium devoid of choline (Fig. 3B). Compared with control cells (Fig. 3C), more apoptotic nuclei (assessed by TUNEL staining) were identified in choline-deprived cells (Fig. 3D). Primary neuronal cells appeared to be more sensitive to choline deprivation than were PC12 cells since significantly more apoptosis was seen in primary cells at an earlier time point than PC12 cells (48 h vs. 60 h; Fig. 4). In both primary neurons and PC12 cells deprived of choline, we observed a laddering pattern characteristic of apoptosis when genomic DNA was resolved with an agarose gel (Fig. 4, insets).

We found that primary cells deprived of choline for $36 \mathrm{~h}$ could be rescued from apoptosis by addition of choline $(100 \%$ viable at 72 h vs. $3 \%$ in-deficient medium, $P<0.01)$, lysophosphatidylcholine ( $73 \%$ viable at $72 \mathrm{~h} ; P<0.01)$, or phosphocholine $(77 \%$ viable at $72 \mathrm{~h}$; $P<0.01)$. The addition of PtdCho did not rescue cells $(6 \%$ viable at $72 \mathrm{~h})$.

\section{Choline and metabolites}

In both cell types, most of the intracellular choline moiety existed as PtdCho (Fig. 5). The next most
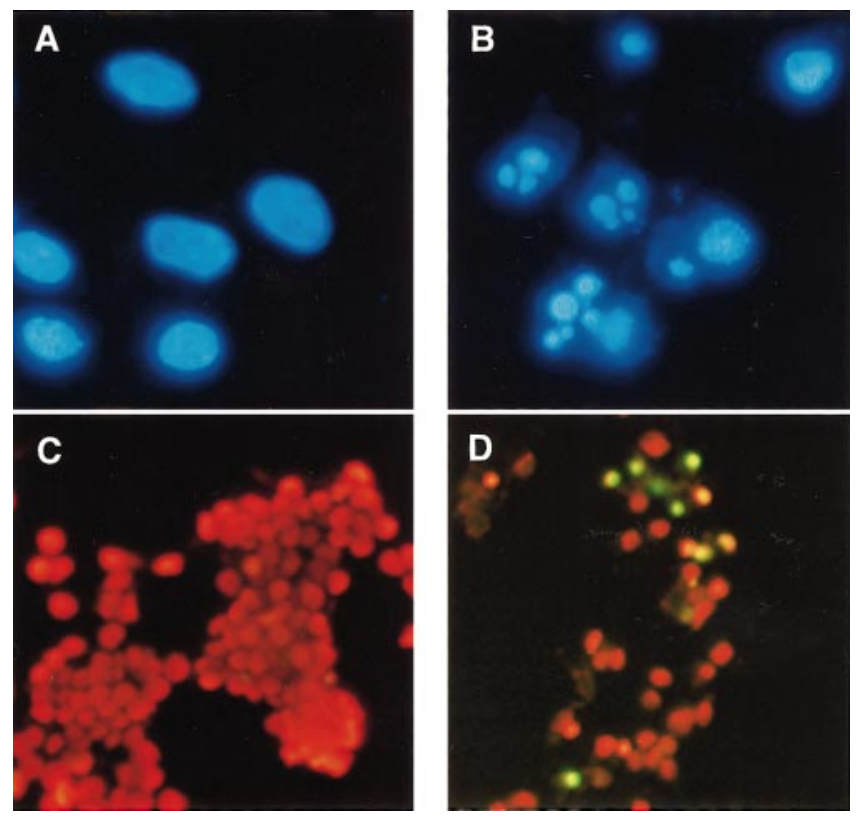

Figure 3. Choline deprivation induces cell death via apoptosis. Primary neuronal cultures were prepared as described in Materials and Methods. At day 3 in culture, apoptotic cells were identified by nuclear morphology $(A, B)$ as well as end-labeling of DNA strand breaks $(C, D)$ with terminal deoxynucleotidyl transferase (TdT) and FITC-coupled nucleotides (green). Nonapoptotic cells' nuclei were visualized with ethidium homodimer (red). $A, C=\operatorname{control} ; B, D=$ choline deficient.

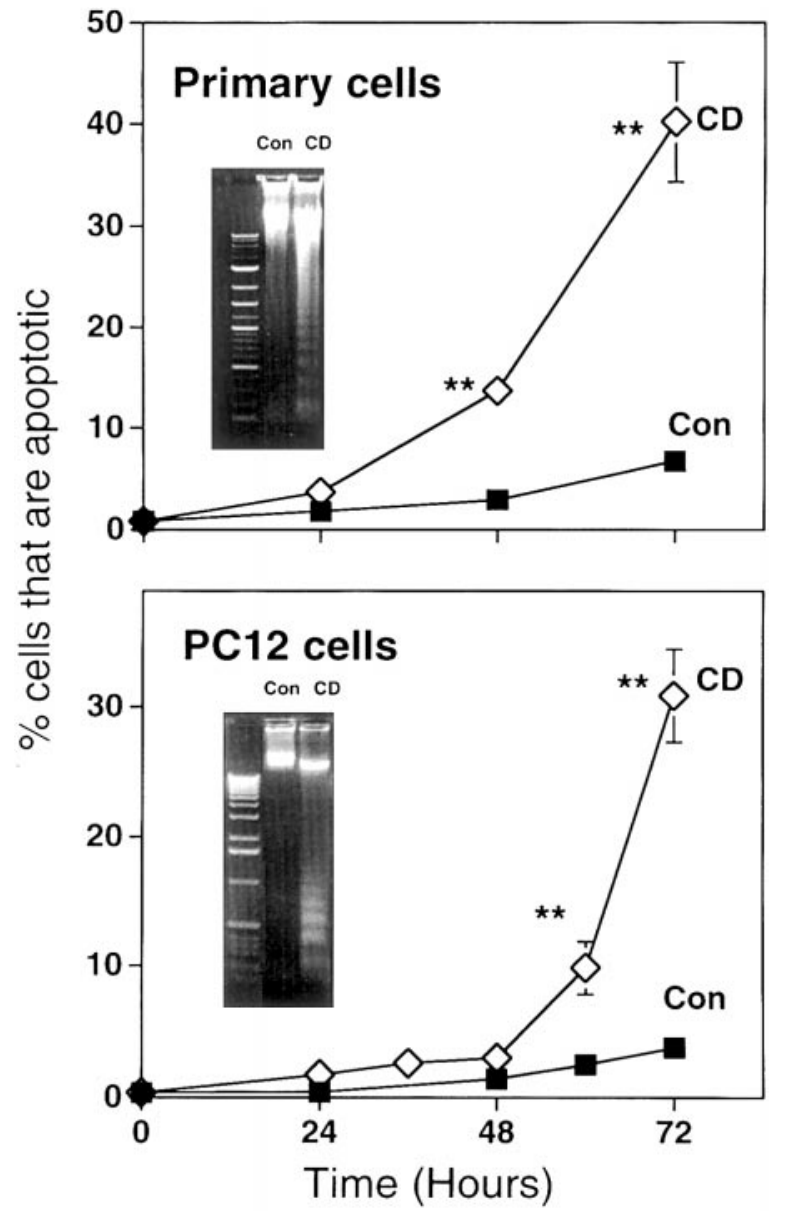

Figure 4. After choline deprivation, primary cells undergo apoptosis at an earlier time than do PC12 cells. Cells were prepared and cultured as described in Materials and Methods. At the times indicated, cells were fixed with $4 \%$ paraformaldehyde and stained with $2 \mu \mathrm{g} / \mathrm{ml}$ Hoechst 33258. Percentage of total cells that were apoptotic was determined by dividing the number of cells with fragmented and condensed nuclei by the total cells counted $(>200$ cells $/$ slide $)$. Con $=$ control, $\mathrm{CD}=$ choline deficient. Data represent means $\pm \mathrm{SE}$, $n=5$ /point. $* * P<0.01$. Insert: DNA laddering in cholinedeprived primary neurons and intact DNA from control neurons. DNA was extracted and separated by electrophoresis as described in Materials and Methods.

abundant choline ester was phosphocholine. Unesterified choline concentrations were $\sim 4 \%$ of that in PtdCho (Fig. 5). Primary neuronal culture contained lower levels of choline, phosphocholine, and PtdCho when compared with PC12 cells on a per DNA basis (Fig. 5). PC12 cells contained slightly more DNA on average than did the primary cells, but the difference was not statistically significant ( $14 \pm 0.45$ vs. $12 \pm 1.12 \mu \mathrm{g}$ DNA/ $10^{6}$ cell, $P>0.32$ ). Upon choline deprivation, choline and phosphocholine concentrations dropped dramatically to the barely detectable range $(0.1-1 \mathrm{pmol} / \mu \mathrm{g}$ protein) in both cell models. This occurred within $24 \mathrm{~h}$ in primary cells and $48 \mathrm{~h}$ in PC12 cells. In primary neurons growing in choline-sufficient medium, PtdCho concentrations increased with time in culture; in PC12 cells growing in choline-sufficient medium, PtdCho concentrations stayed relatively constant (Fig. 5). Ptd- 

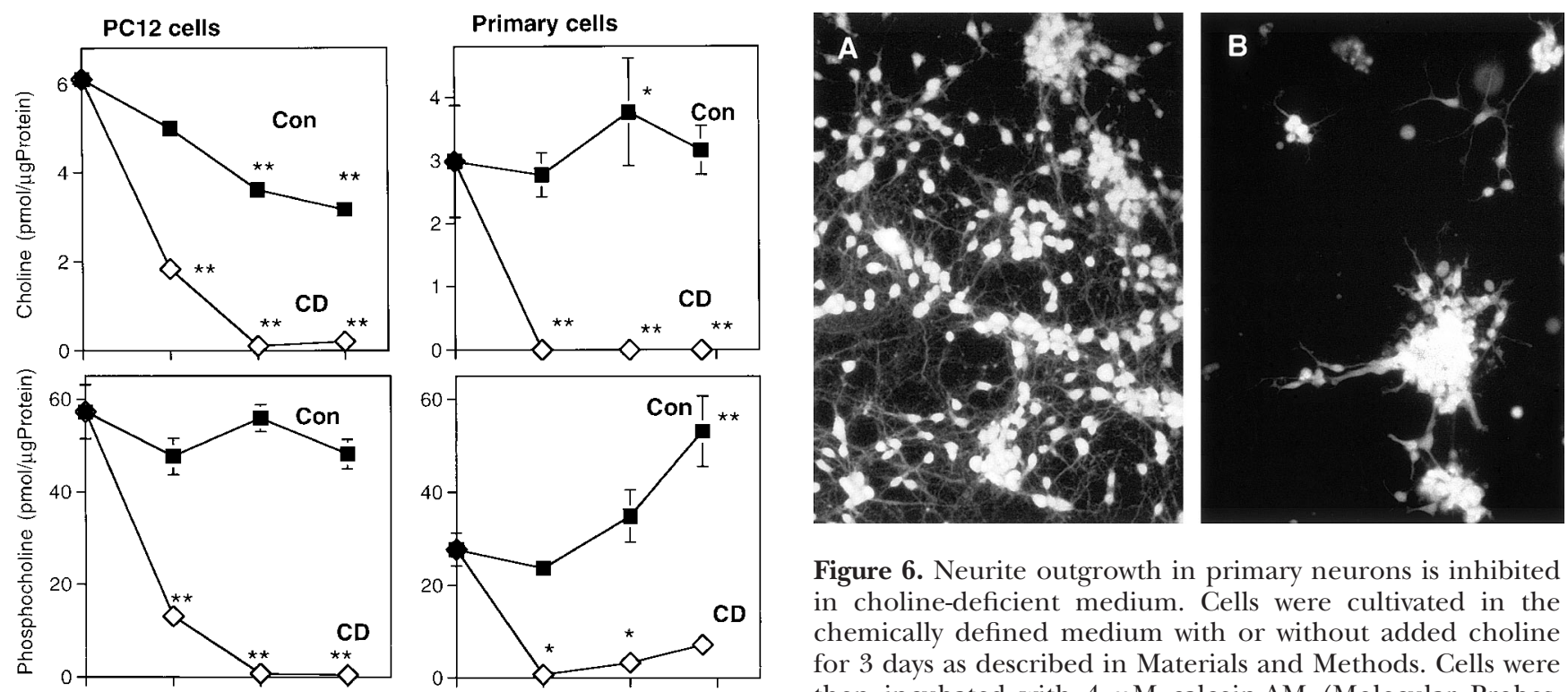

Figure 6. Neurite outgrowth in primary neurons is inhibited in choline-deficient medium. Cells were cultivated in the chemically defined medium with or without added choline for 3 days as described in Materials and Methods. Cells were then incubated with $4 \mu \mathrm{M}$ calcein-AM (Molecular Probes, Eugene, OR) for $20 \mathrm{~min}$. A) In choline-sufficient medium, cells form an extensive outgrowth of neuronal processes. $B$ ) In choline-deficient medium, cells form fewer neurites $(200 \times)$.

plete medium (19). In this study, we found that Cer levels in primary cells deprived of choline were also significantly higher ( twofold that of control) at $72 \mathrm{~h}$ despite the observation that Cer levels increased with time in the control cells (Fig. 7).

Figure 5. Changes in choline, phosphocholine, and phosphatidylcholine concentrations in primary cells and PC12 cells after choline deprivation. Cells were prepared and cultured as described in Materials and Methods. Choline, phosphocholine, and phosphatidylcholine concentrations were analyzed at the times indicated, as described in Materials and Methods. Con $=$ control, $\mathrm{CD}=$ choline deficient. Data represent means $\pm \mathrm{SE}, n=8$ /point. $* P<0.05$, $* * P<0.01$ significantly different from corresponding time 0 control.

Cho concentrations decreased in both primary cells and PC12 cells grown in choline-deficient medium (Fig. 5).

\section{Neurite outgrowth}

In the primary neurons in culture, most of the cells had extensive neurite outgrowth, forming an elaborate network of processes within 3 days. This outgrowth was dramatically attenuated in cells grown in choline-deficient medium (Fig. 6). Under the conditions of these experiments, neurite outgrowth was not induced in PC12 cells (data not shown).

\section{Ceramide}

We previously reported that the Cer level in PC12 cells increases with time after choline deprivation whereas it remains relatively constant in cells grown in the com-

\section{DISCUSSION}

We report that choline deficiency induced apoptosis in postmitotic primary neurons established from fetal rat

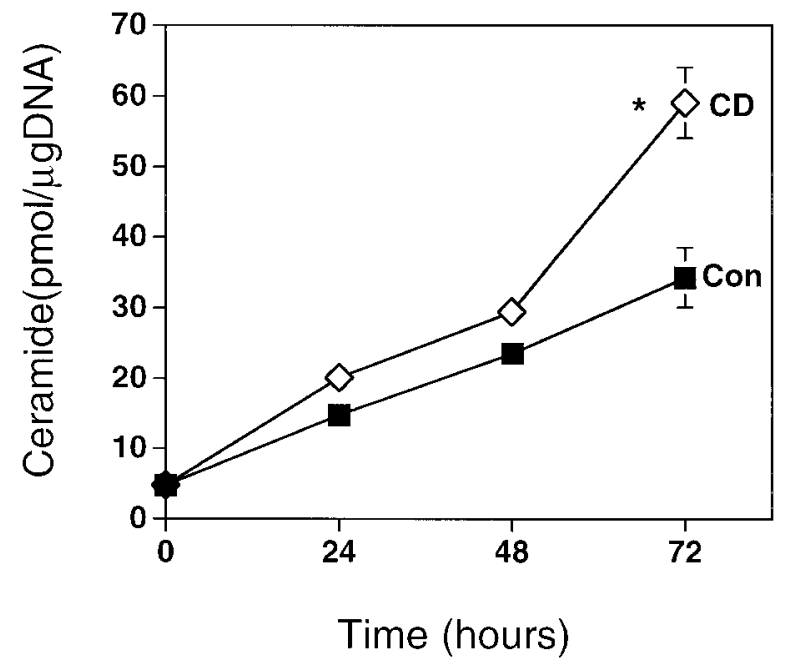

Figure 7. Ceramide concentrations increase in primary neuronal cells after choline deprivation. Cells were cultivated in the chemically defined medium with (Con) or without (CD) added choline for the times indicated as described in Materials and Methods. Cer was measured by HPLC. Data represent means \pm SE, $n=3 /$ point; $* P<0.05$, significantly different from control. 
brains. The primary cells were more sensitive to choline deficiency than were PC12 cells as apoptosis was induced at an earlier time point. In earlier publications, we proposed that induction of apoptosis in choline deficiency was caused by perturbation of cell cycling due to a decrease in membrane PtdCho concentration $(19,20)$ because this choline ester is needed for normal progression through the cell cycle (21). This hypothesis was supported by observations that cells incapable of PtdCho synthesis by the CDP-choline pathway died by apoptosis. For example, a genetic defect in PtdCho biosynthesis or exposure to a PtdCho synthesis inhibitor led to cell cycle arrest as well as apoptosis (26-28). Our current studies in primary neuronal culture illustrate that choline deficiency is capable of inducing apoptosis in neurons by a process independent of perturbation in cell cycling, as these cells normally did not progress past G0/G1 and were not dividing (Fig. 2).

In most cell lines we previously examined, choline deficiency was associated with an absolute decline in PtdCho concentrations $(19,20,29)$, and this was observed for primary cells and PC12 cells in this study (Fig. 5). We had suggested that when PtdCho concentrations fell below a critical level in some subcellular compartments, apoptosis was induced (19). In the current studies of primary cells in culture, we found that we could rescue cells after $36 \mathrm{~h}$ of choline deficiency by adding either phosphocholine or lysophosphatidylcholine (two precursors for PtdCho synthesis), but could not rescue cells with PtdCho itself. We speculate that exogenous PtdCho may not reach some critical subcellular compartment, although endogenously synthesized PtdCho may do so. Alternatively, the critical molecule could be lysophosphatidylcholine rather than PtdCho.

PtdCho is needed for the synthesis of sphingomyelin, which is the reservoir for Cer formation during signaling (30), and its hydrolysis has recently been linked to the characteristic changes of plasma membrane of apoptotic cells (31). We suggested in our previous report that Cer mediates choline deficiency-induced apoptosis based on our observations that Cer concentrations increased before the increase in apoptosis in PC12 cells, that exogenous Cer induced apoptosis, and that inhibition of choline deficiency-induced apoptosis is associated with correction of intracellular Cer levels (19). In several described examples of apoptosis, Cer generated from sphingomyelin hydrolysis mediates apoptosis induced by stimuli such as ultraviolet radiation and activation of the CD95 receptor $(30,32)$. An increase in de novo Cer synthesis in response to chemotherapy or activation of angiotensin II type 2 receptor may also induce apoptosis (33-35). In our primary cells, we observed an association of Cer accumulation with choline deficiency-induced apoptosis, supporting the suggestion of a causal relationship. However, the increase in Cer was not detected until late in the apoptotic process, suggesting that Cer is not the initiating signal for CD apoptosis. Tepper et al. (31) report that Cer accumulation per se is not required for the progression of apoptosis, but that sphingomyelin hydrolysis and subsequent cholesterol efflux are essential for plasma membrane blebbing/vesiculation during the execution phase of apoptosis. It is possible that Cer accumulation during choline deficiency was not directly linked to apoptosis. Cer mediates the effects of NGF on neurite outgrowth of cultured hippocampal neurons, and treatment with cell-permeable Cer enhances cell survival and dendritic outgrowth of cerebellar Purkinje neurons and hippocampal neurons at immature stages $(36,37)$. On the other hand, elevation of Cer within distal neurites impedes neurite growth in cultured rat sympathetic neurons (38) and exposure to exogenous Cer causes retraction of dendrites and apoptosis in immature cerebellar granule cells and mature hippocampal neurons $(39,40)$. Whether the observed Cer increase was responsible for retarded neurite outgrowth (Fig. 7) in our model remains to be determined.

Choline deficiency is of special interest in neurons, as, in the rat, supplemental choline during pregnancy results in life-long enhancement of hippocampal function in offspring (6-10) and the rate of apoptosis in fetal hippocampus is inversely related to the dietary choline intake of the rat dam (17). It has been estimated that more than $50 \%$ of cells born during the development of the central nervous system are eliminated $(41,42)$. Factors modulating apoptosis, such as choline availability, may therefore affect brain development and subsequently brain functions. The primary neuronal culture system appears to be an excellent model to explore the mechanism by which maternal dietary choline intake modulates apoptosis in the fetal brain.

This work was supported by a grant from the National Institutes of Health (AG09525) and by the UNC Clinical Nutrition Research Center (DK56350).

\section{REFERENCES}

1. Food and Nutrition Board Institute of Medicine. (1998) Dietary Reference Intakes: Folate, Other B Vitamins, and Choline, National Academy Press, Washington, DC

2. Newberne, P. M., and Rogers, A. E. (1986) Labile methyl groups and the promotion of cancer. Annu. Rev. Nutr. 6, 407-432

3. Kennedy, E. P., and Weiss, S. B. (1956) The function of cytidine coenzymes in the biosynthesis of phospholipids. J. Biol. Chem. 222, 193-214

4. Exton, J. H. (1994) Phosphatidylcholine breakdown and signal transduction. Biochim. Biophys. Acta 1212, 26-42

5. Hannun, Y. A. (1994) The sphingomyelin cycle and the second messenger function of ceramide. J. Biol. Chem. 269, 3125-3128

6. Meck, W. H., Smith, R. A., and Williams, C. L. (1988) Pre- and postnatal choline supplementation produces long-term facilitation of spatial memory. Dev. Psychobiol. 21, 339-353

7. Meck, W., and Williams, C. (1997) Perinatal choline supplementation increases the threshold for chunking in spatial memory. NeuroReport 8, 3053-3059

8. Meck, W., and Williams, C. (1997) Characterization of the facilitative effects of perinatal choline supplementation on timing and temporal memory. NeuroReport 8, 2831-2835 
9. Meck, W., and Williams, C. (1997) Simultaneous temporal processing is sensitive to prenatal choline availability in mature and aged rats. NeuroReport 8, 3045-3051

10. Loy, R., Heyer, D., Williams, C. L., and Meck, W. H. (1991) Choline-induced spatial memory facilitation correlates with altered distribution and morphology of septal neurons. Adv. Exp. Med. Biol. 295, 373-382

11. Pyapali, G., Turner, D., Williams, C., Meck, W., and Swartzwelder, H. S. (1998) Prenatal choline supplementation decreases the threshold for induction of long-term potentiation in young adult rats. J. Neurophysiol. 79, 1790-1796

12. Jones, J. P., Meck, W., Williams, C. L., Wilson, W. A., and Swartzwelder, H. S. (1999) Choline availability to the developing rat fetus alters adult hippocampal long-term potentiation. Dev. Brain Res. 118, 159-167

13. Cermak, J. M., Blusztajn, J. K., Meck, W. H., Williams, C. L., Fitzgerald, C. M., Rosene, D. L., and Loy, R. (1999) Prenatal availability of choline alters the development of acetylcholinesterase in the rat hippocampus. Dev. Neurosci. 21, 94-104

14. Holler, T., Cermak, J., and Blusztajn, J. (1996) Dietary choline supplementation in pregnant rats increases hippocampal phospholipase D activity of the offspring. FASEB J. 10, 1653-1659

15. Albright, C. D., Tsai, A. Y., Friedrich, C. B., Mar, M. H., and Zeisel, S. H. (1999) Choline availability alters embryonic development of the hippocampus and septum in the rat. Dev. Brain Res. 113, 13-20

16. Albright, C. D., Friedrich, C. B., Brown, E. C., Mar, M. H., and Zeisel, S. H. (1999) Maternal dietary choline availability alters mitosis, apoptosis and the localization of TOAD-64 protein in the developing fetal rat septum. Dev. Brain Res. 115, 123-129

17. Holmes-McNary, M. Q., Loy, R., Mar, M.-H., Albright, C. D., and Zeisel, S. H. (1997) Apoptosis is induced by choline deficiency in fetal brain and in PC12 cells. Dev. Brain Res. 101, 9-16

18. Albright, C. D., Salganik, R. I., Kaufmann, W. K., Vrablic, A. S., and Zeisel, S. H. (1998) A p53-dependent G1 checkpoint function is not required for induction of apoptosis by acute choline deficiency in immortalized rat hepatocytes in culture. $J$. Nutr. Biochem. 9, 476-481

19. Yen, C. L., Mar, M. H., and Zeisel, S. H. (1999) Choline deficiency-induced apoptosis in PC12 cells is associated with diminished membrane phosphatidylcholine and sphingomyelin, accumulation of ceramide and diacylglycerol, and activation of a caspase. FASEB J. 13, 135-142

20. Shin, O. H., Mar, M. H., Albright, C. D., Citarella, M. T., daCosta, K. A., and Zeisel, S. H. (1997) Methyl-group donors cannot prevent apoptotic death of rat hepatocytes induced by choline-deficiency. J. Cell. Biochem. 64, 196-208

21. Jackowski, S. (1994) Coordination of membrane phospholipid synthesis with the cell cycle. J. Biol. Chem. 269, 3858-3867

22. Labarca, C., and Paigen, K. (1980) A simple, rapid and sensitive DNA assay procedure. Anal. Biochem. 102, 344-352

23. Bligh, E. G., and Dyer, W. J. (1959) A rapid method of total lipid extraction and purification. Can. J. Biochem. Physiol. 37, 911-917

24. Pomfret, E. A., daCosta, K., Schurman, L. L., and Zeisel, S. H. (1989) Measurement of choline and choline metabolite concentrations using high-pressure liquid chromatography and gas chromatography-mass spectrometry. Anal. Biochem. 180, 85-90

25. Previati, M., Bertolaso, L., Tramarin, M., Bertagnolo, V., and Capitani, S. (1996) Low nanogram range quantitation of diglycerides and ceramide by high-performance liquid chromatography. Anal. Biochem. 233, 108-114

26. Cui, Z., Houweling, M., Chen, M. H., Record, M., Chap, H., Vance, D. E., and Tercé, F. (1996) A genetic defect in phosphatidylcholine biosynthesis triggers apoptosis in Chinese hamster ovary cells. J. Biol. Chem. 271, 14668-14671
27. Boggs, K., Rock, C., and Jackowski, S. (1995) Lysophosphatidylcholine and 1-O-octadecyl-2-O-methyl-rac-glycero-3-phosphocholine inhibit the CDP-choline pathway of phosphatidylcholine synthesis at the CTP:phosphocholine cytidylyltransferase step. J. Biol. Chem. 270, 7757-7764

28. Miquel, K., Pradines, A., Terce, F., Selmi, S., and Favre, G. (1998) Competitive inhibition of choline phosphotransferase by geranylgeraniol and farnesol inhibits phosphatidylcholine synthesis and induces apoptosis in human lung adenocarcinoma A549 cells. J. Biol. Chem. 273, 26179-26186

29. Albright, C. D., Lui, R., Bethea, T. C., da Costa, K.-A., Salganik, R. I., and Zeisel, S. H. (1996) Choline deficiency induces apoptosis in SV40-immortalized CWSV-1 rat hepatocytes in culture. FASEB J. 10, 510-516

30. Hannun, Y. (1996) Functions of ceramide in coordinating cellular responses to stress. Science 274, 1855-1859

31. Tepper, A. D., Ruurs, P., Wiedmer, T., Sims, P. J., Borst, J., and van Blitterswijk, W. J. (2000) Sphingomyelin hydrolysis to ceramide during the execution phase of apoptosis results from phospholipid scrambling and alters cell-surface morphology [see comments]. J. Cell Biol. 150, 155-164

32. Verheij, M., Bose, R., Lin, X., Yao, B., Jarvis, W., Grant, S., Birrer, M., Szabo, E., and Kolesnick, R. (1996) Requirement for ceramide-initiated SAPK/JNK signalling in stress-induced apoptosis. Nature (London) 380, 75-79

33. Paumen, M., Ishida, Y., Muramatsu, M., Yamamoto, M., and Honjo, T. (1997) Inhibition of carnitine palmitoyltransferase I augments sphingolipid synthesis and palmitate-induced apoptosis. J. Biol. Chem. 272, 3324-3329

34. Shimabukuro, M., Zhou, Y., Levi, M., and Unger, R. (1998) Fatty acid-induced beta cell apoptosis: a link between obesity and diabetes. Proc. Natl. Acad. Sci. USA 95, 2498-2502

35. Lehtonen, J. Y., Horiuchi, M., Daviet, L., Akishita, M., and Dzau, V. J. (1999) Activation of the de novo biosynthesis of sphingolipids mediates angiotensin II type 2 receptor-induced apoptosis. J. Biol. Chem. 274, 16901-16906

36. Brann, A. B., Scott, R., Neuberger, Y., Abulafia, D., Boldin, S., Fainzilber, M., and Futerman, A. H. (1999) Ceramide signaling downstream of the p75 neurotrophin receptor mediates the effects of nerve growth factor on outgrowth of cultured hippocampal neurons. J. Neurosci. 19, 8199-8206

37. Furuya, S., Ono, K., and Hirabayashi, Y. (1995) Sphingolipid biosynthesis is necessary for dendrite growth and survival of cerebellar Purkinje cells in culture. J. Neurochem. 65, 1551-1561

38. de Chaves, E. I. P., Bussiere, M., Vance, D. E., Campenot, R. B., and Vance, J. E. (1997) Elevation of ceramide within distal neurites inhibits neurite growth in cultured rat sympathetic neurons. J. Biol. Chem. 272, 3028-3035

39. Taniwaki, T., Yamada, T., Asahara, H., Ohyagi, Y., and Kira, J. (1999) Ceramide induces apoptosis to immature cerebellar granule cells in culture. Neurochem. Res. 24, 685-690

40. Mitoma, J., Ito, M., Furuya, S., and Hirabayashi, Y. (1998) Bipotential roles of ceramide in the growth of hippocampal neurons: promotion of cell survival and dendritic outgrowth in dose- and developmental stage-dependent manners. J. Neurosci. Res. 51, 712-722

41. Oppenheim, R. W. (1991) Cell death during the development of the nervous system. Annu. Rev. Neurosci. 14, 453-501

42. Thompson, C. B. (1995) Apoptosis in the pathogenesis and treatment of disease. Science 267, 1456-1462

Received for publication November 21, 2000 Revised for publication March 30, 2001. 